of treatment. ${ }^{20}$ This in turn requires greater awareness of the condition.

Senior Registrar,

ROBERT MILLS

Ear, Nose, and Throat Department,

King's College Hospital, London SE5 9RS

1 Chandler JR. Malignant otitis externa. Laryngoscope 1968;78:1257-94.

2 Chandler JR. Pathogenesis and treatment of facial paralysis due to malignant otitis externa. Ann Otol Rhinol Laryngol 1972;81:648-58.

3 Schwartz GA, Blumenkrantz MJ, Studmaker WHL. Neurologic complications of malignant otitis externa. Neurology 1971;21:1077-84.

4 Joachims HZ. Malignant external otitis in children. Arch Otolaryngol 1976;102:236-7.

5 Coser PL, Stamm AEC, Lobo RC, Pinto JA. Malignant otitis externa in infants. Laryngoscope 1980;90:312-6.

6 John AC, Cheeseman AD. Malignant otitis externa. Hospital Update 1979;5:589-99.

7 Aldous EW, Shin JB. Far advanced malignant external otitis: report of a survival. Laryngoscope 1973;83:1810-5.
8 Chandler JR. Malignant otitis: further considerations. Ann Otol Rhinol Laryngol 1977;86:417-28. 9 Morganstein KM, Seung HI. Pseudomonas mastoiditis. Lanyngoscope 1971;81:200-15.

10 Wilson DF, Pulec JL, Linthicum FH. Malignant otitis externa. Arch Otolanyngol 1971; 93:419-22. 1 DasGupta PK. Malignant otitis: a case for remembering the rarities. Geriatric Medicine 1985;15:8. progressive necrotising "malignant" external otitis. Lanngoscope 1984;94:363-6. progressive necrotising "malignant" external otitis. Lanyngoscope 1984;94:363-6. computed tomography and radionuclides in evaluation. Radiology 1983;149:745-9.

computed tomography and radionuclides in evaluation. Radiology $1983 ; 149: 745-9$.
Garty I, Rosen G, Holdstein Y. The radionucleotide diagnosis, evaluation and follow up of marty I, Rosen G, Holdstein Y. The radionucleotide diagno
malignant otitis externa. $\mathcal{F}$ Laryngol Ool 1985;99:109-15.

15 Uri N, Kitzes R, Meyer W, Schuchman G. Necrotising external otitis: the importance of prolonged drug therapy. I Laryngol Otol 1984;98: 1083-5.

16 Youngs RP, Bagley J. Sphenoidal sinusitis secondary to malignant otitis externa. $f$ Lanyngol Otol (in press).

17 Ostfeld E, Segal M, Czernoblinsky B. Malignant external otitis: early histopathologic changes and pathogenic mechanism. Lanyngoscope 1981;91:965-70.

18 Meyerhoff WL, Gates GA, Montalbo PJ. Pseudomonas mastoiditis. Laryngoscope 1977;87: 483-92.

19 Raines JM, Schindler RA. The surgical management of malignant external otitis. Lanyngoscope 1980;90:369-78.

20 Doroghazi RM, Nadol JB, Hyslop NE Jr, et al. Invasive external otitis: report of 21 cases and review of literature. Am $\mathcal{J}$ Med 1981;71:603-14.

\title{
Surgical treatment of male pattern baldness
}

In an image conscious society a high premium is attached to youthful appearance. Baldness is unfashionable. Publicity and intrigue surrounding the alleged treatment of famous heads and extensive advertising by some private clinics have heightened public interest.

Various classifications have been proposed, ${ }^{12}$ but the essential feature of male pattern baldness is that hair is lost most obviously in the frontal region and at the vertex. Parieto-occipital growth is spared, perhaps because of a differential response by hair follicles to circulating androgens. ${ }^{3}$ A permanent "cure" could be achieved in theory if some of these unaffected follicles could be transferred to the bald area without leaving obvious defects at the donor site. This may be achieved in practice by free grafting of small discs (punch grafts) ${ }^{4}$ or thin strips ${ }^{5}$ of hair bearing skin or by transposing vascularised hairy flaps. ${ }^{16-10}$ The bald area may be reduced by staged excision as an adjunctive procedure. $^{2}$

The choice of technique (or combination of techniques) depends on individual requirements. Punch grafting has gained great popularity because of its simplicity. Discs of occipital scalp are excised with a punch similar to that used by dermatologists for skin biopsy. A $4 \mathrm{~mm}$ disc will contain about 12 to 15 hairs. At each visit between 10 and 60 such discs (depending on the endurance of both patient and surgeon) may be transferred to recipient sites prepared by excising discs of bald scalp with a slightly smaller punch. After grafting the original hairs fall out after about two weeks with permanent growth beginning two to three months later. The procedure may be repeated at intervals. Very careful planning is essential to minimise a tufted appearance of the grafts. This is often noticeable at the frontal hairline, and a 5-7 mm wide strip may provide a more acceptable contour. A combination of these two methods may be used to cover a substantial bald area, but the procedure is very tedious and time consuming.

Transposition of vascularised hairy scalp flaps has the advantage of transferring a much larger area of hair in a single operation without a postoperative delay in growth. Greater surgical skill and judgment are required, since the attachment of the flap limits its mobility. Design is crucial in providing a flap of adequate size which will reach the required recipient site with an assured blood supply-and with hair growing in the correct direction. It must be possible to close the donor site directly. The number and variety of published flap configurations attest to the difficulty of meeting these requirements. Satisfying results may be produced, however, particularly in the frontal region.

Scalp reduction uses the principle of staged excision to reduce the size of a bald patch over a series of up to four operations. At each procedure a segment of scalp is removed and the resulting defect closed directly. Between operations the surrounding tissues stretch, effectively expanding the hair covered scalp. For isolated baldness at the vertex this may be an adequate treatment alone, but more usually it is combined with free grafting. The technique of tissue expansion using inflatable prostheses has provided another option. " This has proved very effective in the treatment of alopecia of congenital or traumatic origin.

Reconstructive surgeons have been reserved in their enthusiasm for treating baldness. Their attitude stems in part from the tedious nature of some of the methods described and in part from the inadequate results frequently seen. Clearly, however, there is a public demand-and one which will continue to be satisfied by less well qualified personnel if reconstructive surgeons are unable to provide the service.

Consultant Plastic and Reconstructive Surgeon,

BARRY M JONES

The Hospital for Sick Children,

London $\mathrm{WCl}$; and

University College Hospital,

London WCIE 6AU

1 Juri J. Use of parieto-occipital flaps in the surgical treatment of baldness. Plast Reconstr Surg 1975;55:456-60.

2 Bell ML. Role of scalp reduction in the treatment of male pattern baldness. Plast Reconstr Surg 1982;69:272-7.

3 Takashima I, Adachi K, Montagna W. Studies of common baldness in the stumptailed macaque. IV. In vitro. Metabolism of testosterone in the hair follicles. F Invest Dermatol 1970;55:329-34.

4 Orentreich N. Autografts in alopecias and other selected dermatological conditions. Ann NYAcad Sci 1959;83:463-79.

5 Vallis CP. Surgical treatment of the receding hair line: a report of a case. Plast Reconstr Surg 1964;33:247-52.

6 Lamont ES. A plastic surgical transformation; report of a case. Western fournal of Surgery 1957;65:164-5.

7 Elliot RA. Lateral scalp flaps for instant results in male pattern baldness. Plast Reconstr Surg 1977;60:699-703.

8 Juri J, Juri C, Arufe HN. Use of rotation scalp flaps for treatment of occipital baldness. Plast Reconstr Surg 1978;61:23-6.

9 Nataf J. Lambeaux due cuir chevelu et etude comparative avec les autres techniques de transplantation. Ann Chir Plast 1978;23:176-82.

10 Dardour JC. Treatment of male pattern baldness with a one stage flap. Aesth Plast Surg 1985;9:109-12.

11 Radovan C. Breast reconstruction after mastectomy using the temporary expander. Plast Reconstr Surg 1982;69:195-208. 